\title{
Métodos de inoculação de Fusarium solani e Sclerotium rolfsii em meloeiro
}

\author{
Geovane de Almeida Nogueira, ${ }^{1,2}$; Shamyra Georgia de Azevedo e Silva ${ }^{1,3}$; Cheylla Magdala de Sousa Linhares ${ }^{1,3}$; \\ Márcia Michelle de Queiroz Ambrósio ${ }^{1,4}$; Glauber Henrique de Sousa Nunes ${ }^{1,4}$
}

\begin{abstract}
${ }^{1}$ Universidade Federal Rural do Semiárido - UFERSA - Av. Francisco Mota, 572, Bairro Costa e Silva - Mossoró-RN, Brasil, CEP: 59.625- 900, ${ }^{2}$ Graduando em Agronomia UFERSA, Av. Francisco Mota, 572, Bairro Costa e Silva - Mossoró-RN, Brasil, CEP: 59.625- 900, ${ }^{3}$ Doutorandas em Fitotecnia, UFERSA, Av. Francisco Mota, 572, Bairro Costa e Silva - Mossoró-RN, Brasil, CEP: 59.625- 900, ${ }^{4}$ Professores do Centro de Ciências Agrárias da UFERSA Av. Francisco Mota, 572, Bairro Costa e Silva - Mossoró-RN, Brasil, CEP: 59.625- 900,
\end{abstract} Autor para correspondência: Shamyra Georgia de Azevedo e Silva (shamyrageorgia@hotmail.com) Data de chegada: 27/10/2017. Aceito para publicação em: 27/03/2018.

$10.1590 / 0100-5405 / 187147$

\section{RESUMO}

Nogueira, G.A.; Silva, S.G.A.; Linhares, C.M.S.; Ambrósio, M.M.Q.; Nunes, G.H.S. Métodos de inoculação de Fusarium solani e Sclerotium rolfsii em meloeiro. Summa Phytopathologica, v.45, n.1, p.59-63, 2019.

A podridão-do-colo do meloeiro, causada por Fusarium solani (Mart.). e a murcha do Sclerotium, causada pelo patógeno Sclerotium rolfsii Sacc., são importantes doenças que acometem o meloeiro. Metodologias adequadas de inoculação destes patógenos nas culturas são de grande importância para diversos estudos envolvendo o controle destas doenças, como a resistência de acessos de meloeiro. Desta forma, este trabalho teve como objetivo determinar métodos de inoculação de $F$. solani e $S$. rolfsii em meloeiro, com intuito de verificar uma metodologia de inoculação adequada e eficiente para estudos com os referidos patógenos. Dois experimentos foram conduzidos em casa de vegetação. No primeiro experimento estudou-se 4 métodos de inoculação para $F$. solani em 5 acessos de meloeiro. O segundo, testou-se 5 métodos de inoculação para $S$. rolfsii em 4 acessos da mesma cultura. $\mathrm{O}$ delineamento experimental foi em blocos casualizados com 5 repetições. Os métodos de inoculação utilizados foram: inoculação com palito de dente colonizado com estruturas do patógeno, discos de BDA com estruturas do fungo, infestação do solo com arroz colonizado com estruturas do fungo e infestação do solo com milho colonizado com estruturas do fungo. Para o $S$. rolfsii foi acrescentado o método dos escleródios. Em ambos os experimentos foram utilizadas sementes de melão das cultivares Iracema, Olimpic, A-16, A-50 e A-15, exceto A-15 para o fungo $S$. rolfsii. Utilizou-se a macro SAS F1_LD_F1 para realizar a análise de variância. Para o patógeno $F$. solani, as metodologias do palito e arroz infestado foram as mais eficientes. Já o método do arroz infestado foi o mais eficiente para o fungo $S$. rolfsii.

Palavras-chave: Palavras-chave: Cucumis melo, Patógenos habitantes do solo, Metodologias

\section{ABSTRACT}

Nogueira, G.A.; Silva, S.G.A.; Linhares, C.M.S.; Ambrósio, M.M.Q.; Nunes, G.H.S. Methods for inoculation of Fusarium solani and Sclerotium rolfsii in melon plants. Summa Phytopathologica, v.45, n.1, p.59-63, 2019.

Melon rot, caused by Fusarium solani (Mart.), and Sclerotium wilt, caused by the pathogen Sclerotium rolfsii Sacc, are important diseases that affect melon plants. Suitable methodologies for the inoculation of these pathogens in plants are of great importance to studies involving the control of these diseases, such as resistance of different melon accessions. Thus, the present study aimed to determine methods for the inoculation of $F$. solani and $S$. rolfsii in melon plants in order to verify a suitable and efficient inoculation methodology for studies with these pathogens. Two experiments were conducted in a greenhouse. In the first experiment, 4 inoculation methods were studied for $F$. solani in 5 melon accessions. In the second experiment, 5 inoculation methods were tested for $S$. rolfsii in 4 accessions of the same crop. Experimental design was in randomized blocks with 5 replicates. The used inoculation methods were: inoculation with toothpicks colonized with structures of the pathogen, PDA discs with structures of the fungus, soil infestation with rice colonized with structures of the fungus, and soil infestation with corn colonized with structures of the fungus. For $S$. rolfsii, the method of sclerotia was added. In both experiments, melon seeds of the cultivars Iracema, Olimpic, A-16, A-50 and A-15 were employed, except A-15 for $S$. rolfsii. The SAS F1_LD_F1 macro software was adopted to perform the analysis of variance. For $F$. solani, toothpick and infested rice were the most efficient methodologies. Infested rice was the most efficient method for the fungus S. rolfsii.

Keywords: Cucumis melo, Soilborne pathogens, methodologies

O meloeiro (Cucumis melo L.) é pertencente à família das Cucurbitáceas. Seu fruto tem uma grande aceitação no Brasil e no mundo, sendo consumido em larga escala em vários países. O Brasil é o terceiro maior produtor mundial desta cultura (6).

O Nordeste brasileiro detém mais de $90 \%$ da produção nacional de melão (17), sendo os Estados do Rio Grande do Norte e Ceará os maiores produtores respectivamente (9). A alta produtividade e qualidade dos frutos colhidos se devem as condições edafoclimáticas da região com temperaturas altas durante todo o ano, alto índice de insolação e luminosidade, baixa umidade do ar, poucas chuvas e presença de solos férteis, favorecendo o desenvolvimento de frutos com elevados teores de sólidos solúveis totais e com boa aparência condicionando um fruto altamente qualificado para exportação (4).

Porém, o cultivo intensificado nesta região tem contribuído para ocorrência de várias doenças, entre elas, as ocasionadas por patógenos habitantes do solo (11). A podridão radicular, causada por estes fitopatógenos, prejudica a absorção de água e nutrientes devido aos danos causados as raízes das plantas afetadas. Quando não controladas, 
estas doenças geram grandes perdas na produtividade, reduz a qualidade dos frutos, inviabilizando seu cultivo (8).

Dentre esses problemas, a podridão-do-colo do meloeiro, causada por Fusarium solani (Mart.)., é uma das mais importantes observadas. Há relatos da associação deste fitopatógeno com a ocorrência do colapso do meloeiro, onde junto com diversos patógenos habitantes do solo como Macrophomina phaseolina, Monosporascus cannonballus, Rhizoctonia solani e Sclerotium rolfsii causa um complexo de doenças (2).

O fungo $F$. solani pode permanecer viável durante anos no solo, devido à produção de clamidósporos, estrutura de resistência que pode ser dispersa também por meio de práticas onde haja o movimento do solo infestado (7). Sua disseminação no campo pode ser através do vento, implementos agrícolas e a água. A fusariose é caracterizada pela clorose e necrose das folhas, posteriormente à murcha, nanismo e o escurecimento vascular, levando a planta a ter uma redução na sua produtividade e até a morte (14).

A murcha do Sclerotium, causada pelo patógeno Sclerotium rolfsii Sacc., é outra doença encontrada na cultura do meloeiro, produz micélio branco entrelaçado formado na superfície do solo e ao redor das plantas infectadas (19). Este fungo pode ocasionar tombamentos, murcha e podridão em raízes e no colo. Na falta de hospedeiro, pode sobreviver no solo através dos escleródios, dificultando assim seu controle (13).

Uma opção eficiente e econômica para o controle de fungos fitopatogênicos habitantes do solo é a utilização de cultivares resistentes, além disso, após a proibição do uso do brometo de metila, buscam-se alternativas para o manejo destes patógenos. Tanto para a obtenção de fontes de resistência a doenças, como para ensaios que busquem formas de controle é necessária uma metodologia eficiente e confiável de inoculação, que possibilite a infecção da planta e o desenvolvimento típico dos sintomas ocasionados no campo. Devido à importância da cultura do meloeiro para o Nordeste brasileiro e a grande ocorrência dos fungos fitopatogênicos habitantes do solo, ocasionando a redução na produção, este trabalho teve como objetivo determinar métodos de inoculação de $F$. solani e $S$. rolfsii em meloeiro, com intuito de verificar uma metodologia de inoculação adequada e eficiente para futuros estudos com os referidos patógenos.

\section{MATERIAL E MÉTODOS}

Foram realizados dois experimentos em casa de vegetação no Centro de Ciências Agrárias da Universidade Federal Rural do SemiÁrido (UFERSA), localizado no município de Mossoró-Rio Grande do Norte (RN), Brasil, no período de julho de 2016 a maio de 2017.

No primeiro experimento estudou-se 4 métodos de inoculação para $F$. solani em 5 acessos de meloeiro. O segundo, testou-se 5 métodos de inoculação para $S$. rolfsii em 4 acessos da mesma cultura. $\mathrm{O}$ delineamento experimental foi em blocos casualizados com 5 repetições, sendo uma planta por vaso.

Os métodos de inoculação foram: 1. Inoculação com palito de madeira "do tipo palito de dente" colonizado com estruturas do patógeno (12); 2. Discos de BDA (batata-dextrose-ágar) com estruturas do fungo (3); 3. Infestação do solo com arroz colonizado com estruturas do fungo (5), e 4. Infestação do solo com milho colonizado com estruturas do fungo (5). Para o $S$. rolfsii foi acrescentado o método dos escleródios (3).

Em ambos os experimentos foram utilizadas sementes de melão das cultivares Iracema, Olimpic, A-16, A-50 e A-15, exceto A-15 para o fungo $S$. rolfsii, sendo estas provenientes do Banco de Germoplasma de Curcubitáceas da UFERSA.

As sementes foram desinfestadas com álcool $70 \%$, hipoclorito de sódio a $1 \%$ por um minuto, lavadas com água destilada e esterilizada. Em seguida, foram semeadas 2 sementes por vaso, em substrato TropstratoHT Hortaliças ${ }^{\circledR}$, autoclavado por 2 horas a $120{ }^{\circ} \mathrm{C}$, sendo 1 hora por dia, com intervalo de 24 horas. Após a germinação foi realizado o desbaste, deixando uma planta/vaso.

Os isolados dos patógenos foram obtidos da micoteca do Laboratório de Microbiologia e Fitopatologia da UFERSA. Antes da produção do inóculo, para ambos os microrganismos, foi realizado o teste de patogenicidade pelo método do palito de dente infestado com estruturas dos fungos.

No preparo do inóculo, para o método do palito (10) foram utilizadas pontas de palitos de dente $(1,5 \mathrm{~cm})$, inseridas verticalmente em um disco de papel de filtro com o mesmo diâmetro interno da placa de Petri. Depois de colocados dentro das placas, com a parte afilada dos palitos voltada para cima, o conjunto todo foi esterilizado a $121^{\circ} \mathrm{C}$ em autoclave, por 30 minutos, conforme metodologia de Medeiros (12).

Em seguida, verteu-se meio de cultura BDA, deixando expostos cerca de $2 \mathrm{~mm}$ da extremidade dos palitos. Após a solidificação do meio BDA, foram repicados cinco discos de $0,5 \mathrm{~cm}$ de diâmetro com estruturas do fungo, distribuídos equidistantes. As placas foram mantidas por dez dias, em estufa tipo D.B.O (demanda bioquímica de oxigênio) a $28 \pm 2{ }^{\circ} \mathrm{C}$ para a completa colonização dos palitos. Os palitos foram inseridos no caule das plantas, próximo à superfície do solo (aproximadamente $\pm 0,5 \mathrm{~cm}$ ) (12).

Para os tratamentos cuja inoculação foi deposição de discos de BDA com estruturas do fungo no colo da planta, retirou-se discos de $0,5 \mathrm{~cm}$ de diâmetro das bordas das colônias e depositaram-se 8 discos no colo de cada planta.

Os métodos do arroz e milho colonizados foram preparados de forma similar, onde ambos passaram, separadamente, por um processo de autoclavagem a $120^{\circ} \mathrm{C}$ por 30 minutos, sendo repetida a esterilização após 24 horas. Cinco discos com estruturas dos fungos, previamente cultivados em meio de cultura $\mathrm{BDA}+$ tetraciclina $(0,05 \mathrm{~g} / \mathrm{L})$, foram transferidos para cada frasco contendo arroz e milho umedecidos com água destilada/esterilizada. Os frascos foram mantidos em estufa tipo D.B.O a $28 \pm 2{ }^{\circ} \mathrm{C}$, por 15 dias, até a colonização completa dos substratos. Para os dois métodos utilizaram-se 8 gramas de inóculo na superfície do substrato (16).

A produção de estrutura de resistência (escleródios) de $S$. rolfsii consistiu em transferir um escleródio para placa de Petri contendo uma fina camada de BDA + tetraciclina $(0,05 \mathrm{~g} / \mathrm{L})$, mantendo-se as placas em estufa tipo D.B.O a $28 \pm 2{ }^{\circ} \mathrm{C}$, por 30 dias, até a completa formação dos escleródios, os quais foram removidos com auxílio de pincel de cerdas macias. Foram colocados 8 escleródios na superfície do substrato contido nos vasos dos tratamentos (3).

A inoculação foi realizada aos 15 dias após a semeadura e a avaliação da severidade da doença aos 30 dias após a inoculação. Para F. solani utilizou-se a escala de notas proposta por Porto (15), em que 1: planta sadia; 2: de 1 a $30 \%$ de tecidos infectados; 3: de 31 a $60 \%$ de tecidos infectados; 4 : maior que $60 \%$ de tecidos infectados; e 5: planta morta. A escala utilizada para a avaliação do $S$. rolfsii foi a proposta por Ambrósio et al. (1), em que 0: sem sintoma; $1: 3 \%$ de tecidos infectados; 2: $10 \%$ de tecidos infectados; 3: $25 \%$ de tecidos infectados; 4: $50 \%$ de tecidos infectados; e 5: planta morta.

Utilizou-se a macro SAS F1_LD_F1 para realizar a análise de variância (ATS), onde foi testado o efeito de métodos de inoculação, 
acessos e a interação entre os fatores. As estimativas do ordenamento médio (Rank médio) foram obtidas pelas macro LD_CI. As macros foram obtidas no website do Professor Edgard Brunner da Universidade de Gotting (<http://www. ams.med.uni goettingen.de/de/sof/ld/makros. html $>$ ). A descrição das análises realizadas no presente trabalho está detalhada no trabalho de Shan \& Madden (18). Em todas as análises foram utilizadas o nível nominal de significância de 5\% de probabilidade $(\alpha=0,05)$.

\section{RESULTADOS E DISCUSSÃO}

Na severidade da doença no meloeiro, a análise da variância mostrou que houve efeito significativo entre os métodos e acessos, independente do patógeno. Já na interação método x acesso, houve efeito significativo apenas para o patógeno F. solani (Tabela1).

Tabela 1. Valor de F obtidos conforme análise de variância (ATS) não paramétrica para severidade avaliada em acessos de meloeiro inoculados com Fusarium solani e Sclerotium rolfsii Mossoró-RN, 2016.

\begin{tabular}{lcc}
\hline \multirow{2}{*}{ FV } & \multicolumn{2}{c}{ Anova - (ATS) } \\
\cline { 2 - 3 } & F. solani & S. rolfsii \\
\hline Métodos & $11,31^{* *}$ & $18,76^{* *}$ \\
Acessos & $2,86^{* *}$ & $4,31^{* *}$ \\
M x A & $2,26^{* *}$ & $0,81^{\mathrm{ns}}$ \\
\hline
\end{tabular}

**: F Significativo a 0,05 por Anova - (ATS).

Com relação aos métodos de inoculação para o patógeno $F$. solani, para a maioria dos acessos, a metodologia do palito foi a que melhor mostrou a sintomatologia nas plantas e com maior rapidez, seguido do método do arroz infestado. Estas se mostraram mais eficientes e permitiram uma melhor discriminação entre os acessos utilizados no que diz respeito à severidade da doença (Tabela 2).

O sucesso com a utilização do método do palito de dente infestado se deve ao fato do patógeno ser inserido diretamente na planta, através de uma lesão discreta, facilitando a infecção e colonização do patógeno na planta e reduzindo o tempo para o aparecimento dos sintomas. Com isso, facilita a discriminação da resistência de acessos aos patógenos, além de ajudar na análise de algumas formas de manejo da doença.

Isto demonstra que em um teste de resistência de acessos de meloeiro à $F$. solani, o método do palito de dente (invasivo), pode ser o mais eficaz e rápido para conhecer a resistência/suscetibilidade de um material, mas talvez, não consiga detectar o real grau de severidade da doença o qual outras metodologias não invasivas poderiam. Devemos ressaltar que, em alguns casos, as metodologias não invasivas se sobressaíram, como para o acesso A-15, que apresentou melhor desempenho pelo método do arroz infestado, ou como os acessos A-16 e Olimpic, onde o método do micélio não diferiu estatisticamente do método palito de dente. Metodologias não invasivas imitam o que ocorre no ambiente, quando uma planta não tem ferimento, mas é infectada pela presença das estruturas do patógeno. Desse modo, os métodos do arroz infestado e do micélio podem ser complementares numa possível avaliação de resistência genética para essa cultura e grau de severidade para essa doença.

São escassos os trabalhos que comparam metodologias de inoculação de Fusarium em meloeiro. Entretanto, diversos pesquisadores já estudaram técnicas de inoculação com outros patógenos habitantes do solo. Por exemplo, Tolêdo-Souza e Costa (20), ao testar metodologias de inoculação em plântulas de feijoeiro para o fungo Sclerotinia sclerotiorum apontaram que o método de inoculação da haste utilizando palito de madeira colonizado pelo fungo ocasionou maior severidade da doença, comparado com outras técnicas, como discos de BDA contendo micélio do fungo e método de inoculação das flores utilizando suspensão de ascósporos.

Estes resultados foram semelhantes aos observados no presente trabalho para o fungo $F$. solani, onde o método do palito de madeira foi o que causou maior resposta no grau de severidade da doença. Medeiros et al. (12) ao avaliarem métodos de inoculação de Rhizoctonia solani e Macrophomina phaseolina em meloeiro concluíram que a técnica do palito também foi mais eficiente para discriminar os acessos para doenças, independentemente do isolado utilizado na inoculação.

Para o fungo $F$. solani, a menor severidade da doença foi constatada no método onde se utilizou o milho colonizado com estruturas do patógeno. Isto se deve, possivelmente ao fato da maior dificuldade de colonização dos grãos de milho pelo patógeno, na hora da produção do inóculo. Ou seja, os grãos de milho ficam pouco colonizados, o que pode reduzir a quantidade de estruturas infectivas do patógeno, além disso, este tipo de metodologia (infestação do solo com o patógeno) exige maior período de tempo para o surgimento de sintomas, uma vez

Tabela 2. Nota média e reação de cinco acessos de meloeiro ao isolado de Fusarium solani utilizando quatro métodos diferentes de inoculação. Mossoró-RN, UFERSA, 2017.

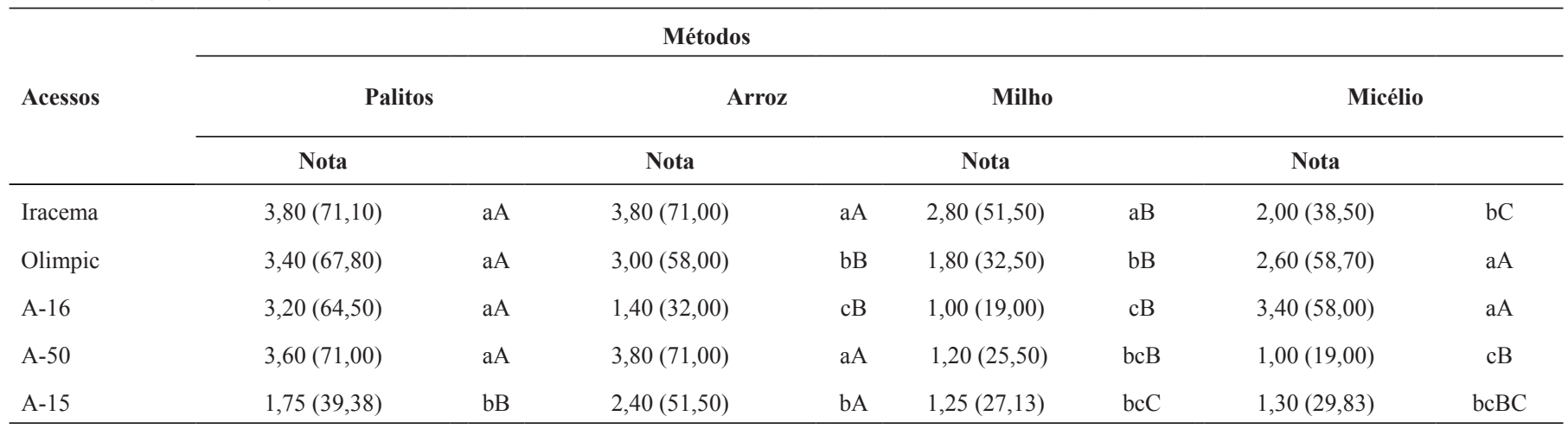

Médias seguidas pela mesma letra maiúscula nas linhas não diferem entre si a 5\% de probabilidade e mesma letra minúscula nas colunas não diferem entre si a $5 \%$

(15). Valores fora dos parênteses $=$ valores reais. Valores dentro dos parênteses $=$ valores referentes ao rank. 
Tabela 3. Nota média e reação de quatro acessos de meloeiro ao isolado de Sclerotium rolfsii utilizando cinco métodos diferentes de inoculação. Mossoró-RN, UFERSA, 2016.

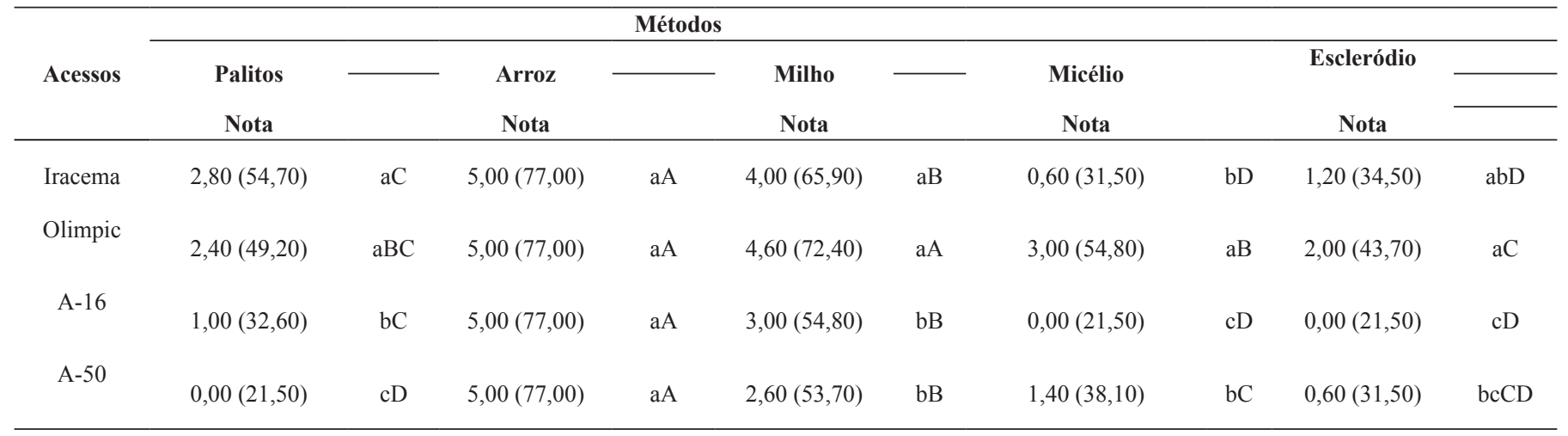

Médias seguidas pela mesma letra maiúscula nas linhas não diferem entre si a 5\% de probabilidade e mesma letra minúscula nas colunas não diferem entre si a 5\% (15). Valores fora dos parênteses $=$ valores reais. Valores dentro dos parênteses $=$ valores referentes ao rank.

que o patógeno precisa se estabelecer no solo, para poder penetrar e iniciar o processo de infecção na planta.

Para os acessos de meloeiro avaliados, todos apresentaram algum tipo de lesão causada pelo fungo $F$. solani, exibindo diferenças apenas no grau de severidade à podridão-do-colo como é possível observar na Tabela 2, apontando que os acessos são suscetíveis ao fungo.

Ao avaliar as metodologias de inoculação para o fungo $S$. rolfsii verificou-se que o método do arroz infestado com estruturas do patógeno ocasionou maior severidade da doença nos acessos estudados (Tabela 3). Observou-se que o arroz ficou bastante colonizado, certamente contribuindo para maior quantidade de estruturas infectivas do patógeno.

Falcão et al. (5) ao avaliar a metodologia do arroz inoculado com fungo para contaminação de solo com propágulos dos fungos $S$. sclerotiorum e S.rolfsii em soja constataram que houve a mortalidade de $100 \%$ das plântulas em solos contaminados com grãos de arroz.

Barbosa et al. (3) ao testarem metodologias de inoculação de $S$. rolfsii em tomateiro concluíram que o tratamento de arroz colonizado foi o método indicado para experimentos que visem a inoculação do patógeno, sem causar ferimentos nas plantas.

Resultados obtidos neste estudo levam à indicação das metodologias de inoculação utilizando-se palito de dente colonizado ( $F$. solani) e arroz infestado ( $F$. solani e $S$. rolfsii) como promissoras para os estudos de resistência e manejo de doenças em acessos de meloeiro para os patógenos estudados. Pode-se ainda assegurar que estes métodos são promissores na identificação de fontes de resistência e diferenciação de genótipos, principalmente de meloeiro, em função da virulência dos patógenos.

\section{AGRADECIMENTOS}

À Universidade Federal Rural do Semi-árido - UFERSA (PICI) e Coordenação de Aperfeiçoamento de Pessoal de Nível Superior (CAPES) pela concessão das bolsas de pesquisa.

\section{REFERÊNCIAS}

1. Ambrósio, M.M.Q.; Dantas, A.C.A.; Martínez-Perez, E.; Medeiros, A.C.; Nunes, G.H.S.; Picó, M.B. Screening a variable germplasm collection of Cucumis melo L. for seedling resistance to Macrophomina phaseolina.
Euphytica. Dordrecht, v.206, p.287-300, 2015.

2. Andrade, D.E.G.T.; Michereff, S.J.; Biondi, C.M.; Nascimento, C.W.A.; Sales Júnior. R. Frequência de fungos associados ao colapso do meloeiro e relação com características físicas, químicas e microbiológicas dos solos. Summa Phytopathologica, Botucatu, v.31, n.4, p.327-333, 2005.

3. Barbosa, R.N.T.; Halfeld-Vieira, B.A.; Necher, K.L.; Souza, G.R. Método para inoculação de Sclerotium rolfsii em tomateiro. Revista Agroambiente, Boa Vista, v.4, n.1, p.49-52, 2010.

4. Costa, N.D.; Dias, R.C.S. Sistema de Produção de melão. Petrolina: Embrapa Semiárido, 2010. Disponível em: <http://www.cpatsa. embrapa.br:8080/sistema_producao/spmelo/plantio.html>. Acesso em: 2 jul. 2016.

5. Falcão, J.V.; Oliri, F.P.; Ávila, V.R.; Mello, S.C.M. Estabelecimento de metodologia para contaminação de solo com propágulos dos fungos Sclerotinia sclerotiorum e Sclerotium rolfsii, e expressão de doença em soja. Brasília: Embrapa Recursos Genéticos e Biotecnologia, 2005. 9p. (Comunicado Técnico, 135).

6. FAO. Food and Agriculture Organization of the United Nations. In: Statistical Yearbook. World food and agriculture. Rome 2013.

7. Fischer, I.H.; Resende, J.A.M. Diseases of Passion Flower (Passiflora spp.). Pest Technology, Kagawa, v.2, n.1, p.1-19, 2008.

8. Garcia-Jimenez, J.; Armengol, J.; Sales, R.; Jordá, C.; Bruton. B.D. Fungal pathogens associated with melon plants collapse in Spain. EPPO Bulletin, Paris, v.30, n.2, p.169-173, 2000.

9. IBGE. Produção agrícola. Rio de Janeiro, 2016. Disponível em: <https:// ww2.ibge.gov.br/home/estatistica/economia/pam/2016/default_xls. shtm>. Acesso em: 1 jan. 2017.

10. Klingelfuss, L.H.; Yorinori, J.T.; Arias, C.A.A; Destro, D. Reaction of soybean cultivars to sudden death syndrome and disease scoring methods for screening resistance. Crop Breeding and Applied Biotechnology, Viçosa, v.2, n.2, p. 257-264, 2002.

11. Maia, L.K.R.; Lima, R.E.M.; Lima, J.S. Importância do meloeiro e aspectos relacionados à resistência a Rhizoctonia solani. Enciclopédia Biosfera, Goiânia, v.9, n.17, p.1609-1622, 2013.

12. Medeiros, A.C.; Melo, D.R.M.; Ambrósio, M.M.Q.; Nunes, G.H.S.; Costa, J.M. Métodos de inoculação de Rhizoctonia solani e Macrophomina phaseolina em meloeiro (Cucumis melo). Summa Phytopathologica, Botucatu, v.41, n.4, p.281-286, 2015.

13. Pandey, M.K.; Sarma, B.K.; Singh, D.P. Biochemical Investigations of Sclerotial Exudates of Sclerotium rolfsii and their Antifungal Activity. Journal of Phytopathology, Berlin, v.155, n.2, p.84-89, 2007.

14. Pereira, R.B.; Pinheiro, J.B.; Carvalho, A.D.F. Identificação e manejo das principais doenças fúngicas do meloeiro. Brasília. Embrapa Hortaliças, 2012, 8p. (Embrapa Hortaliças. Circular Técnica, 112).

15. Porto, M.A.F. Associação de Fusarium solani, Macrophomina phaseolina e Rhizoctonia solani causando podridão radicular em meloeiro sob efeito de adubos verdes. 2015. 73f. Dissertação (Mestre em Fitotecnia) - Universidade Federal Rural do Semiárido, Mossoró. 16. Sánchez, S.; Henríquez, J.L.; Urcola, L.A.; Scott, A.; Gambardella, M. 
Susceptibility of strawberry cultivars to root and crown rot caused by Macrophomina phaseolina. Journal of Berry Research, Amsterdam, v.6, n.3, p.345-354, 2016.

17. Sebrae. O cultivo e o Mercado do melão. Rio de Janeiro, 2016. Disponível em: <http://www.sebrae.com.br/sites/PortalSebrae/artigos/o-cultivo-e-o-mercado-do-melao,5a8837b644134410VgnVCM2000003c74010aRCRD>. Acesso em: 4 jul. 2016.

18. Shan, D.A.; Madden, L.V. Nonparametric Analysis of Ordinal Data in Designed Factorial Experiments. Phytopathology, Saint Paul, v.9, n.1, p.33-43. 2004.

19. Sinclair, J.B.; Backman, P.A. (Ed.). Compendium of soybean diseases. 3.ed. St. Paul: APS Press, 1989. p. 24-27.

20. Tolêdo-Souza, E.D.; Costa, E.J.L.S. Métodos de inoculação de plântulas de feijoeiro para avaliação de germoplasma quanto a resistência a Sclerotinia sclerotiorum (Lib.) De Bary. Pesquisa Agropecuária Tropical, Goiânia, v.2, n.33, p.57-63, 2003. 